sciendo

International Conference KNOWLEDGE-BASED ORGANIZATION

Vol. XXVII No 12021

\title{
IMPACTS OF THE COVID-19 PANDEMIC ON SOCIAL DEVELOPMENT AND ITS IMPLICATIONS FOR THE TRANSITION TO SUSTAINABLE DEVELOPMENT
}

\author{
George BUCĂȚA*, Alexandru-Marius RIZESCU** \\ *"Lucian Blaga" University of Sibiu, Romania \\ **“Nicolae Bălcescu" Land Forces Academy, Sibiu, Romania \\ george.bucata@yahoo.ro, mariusrizescu@yahoo.com
}

\begin{abstract}
The COVID-19 crisis has revealed the vulnerability of people, societies and economies and has forced a rethinking of the economic and social activities of an organization. The crisis requires strong responses based on solidarity, cooperation and responsibility. Socio-economic organizations (associations, cooperatives, alliances, and social enterprises) whose business models are based on these principles can help reshape economies and societies after the crisis.
\end{abstract}

Keywords: social development, sustainable development, economic development, economic transition, COVID-19 economic impact

\section{Introduction}

During the last four years, the Romanian economy has rapidly developed which has been driven mainly by private consumption and has been supported by pro-cyclical fiscal measures. This has led to an increase in inflation, especially in the last two years, the current account deficit was around 4.6\% in 2019. The national debt is moderate according to regional standards and amounts to around $35.0 \%$ of the GDP. The Romanian economy was severely affected by the Covid-19 crisis in early 2020 and requires significant efforts to recover. Romania shows significant transition deficits in most economic sectors. The traffic situation and municipal infrastructure exacerbate regional differences and limit the integration of the value chain and the market. Health infrastructure is below EU standards due to ineffective financial management processes and lack of investment. The energy sector has benefited from private sector involvement, but additional investments are needed to improve efficiency and intensify crossborder connections. The shock of the health crisis at its full performance leaves deep marks on the way in which economies are organized and work globally. Social removal measures, economic intervention measures and solutions adopted by companies show adaptation tests in relation to important changes for all kinds of human activities [4].

While the labour market has become more rigid and overall unemployment remains low, emigration and investment are at stake, inadequate infrastructure tended to generate considerable regional differences. For the Romanian economy, consumption has been a major growth engine in recent years. According to the National Institute of Statistics, consumption supported almost $80 \%$ of the economic growth. Given that in the current context of the COVID-19 crisis, 
a general drop in demand can be observed and Romania needs to consolidate domestic demand in economy and promote the participation of local consumption in total consumption. While consumption increased, much of the growth was supported by imports, causing imbalance. Therefore, it is necessary to restructure the productive sectors of the economy in order to correct external deficits and increase the complexity of the economy. This approach helps increase competitiveness and potential GDP.

The total domestic supply growth model and consequently the current economic growth model raise obvious sustainability issues while being undermined by the twin deficit aspect described above. The current crisis gives Romania the opportunity to restructure production models in all areas of the national economy to develop circular production models that focus on sustainability and responsible management of resources. Supply chain restructuring must also take into account relocation trends that result from the need for geographic proximity and prevention of the effects of unforeseen events, such as global pandemics or natural disasters. This is the only way for the local economy to take advantage of the opportunities for development and integration in the continental value chains that Europe wants to put into operation [5].

Romania's development and convergence processes have depended on EU accession for the past two decades, reflecting massive inflows of foreign direct investment, the lack of a balanced mix of economic policy measures (with adverse effects on the macro-financial stability) and the exodus of the labour force. Given the current challenges in the European and global economy (the transition to a new order), we know that it is of fundamental importance for Romania and the countries of the region to implement a new convergence model based on the efficient redistribution of internal resources and the implementation of a balanced and concentrated mix of economic policies, the acceleration of structural reforms (including capital market development), regional integration and transition to the qualitative dimension. Currently, Romania does have human, financial and digital resources, but faces challenges regarding allocation mechanisms, including the still high bureaucratic burden [2].

\section{COVID-19 Impact on Social Development}

Social advancement contributes to the wellbeing of each person in society, so that they can perform at their full potential. The victory of society is connected to the wellbeing of each citizen. Social improvement implies individual contributions. This requires the expulsion of obstructions so that all citizens can confront their aspirations with certainty and respect. It is around denying to acknowledge that individuals living in destitution will continuously be destitute. When making a difference, individuals move forward on their way to self-confidence. Learning must begin early in life. By contributing in early learning activities, more noteworthy progress can be guaranteed among citizens. Guaranteeing that children have the right start on their learning experiences does make a difference. An open and highquality childcare framework is additionally required for the success of a company. When individuals know that their children are well cared for, they can be more effective at work. When managers have great employees, their businesses are more likely to succeed. When businesses are fruitful, the financial circumstance of a community moves forward. Contributing in great child care programs nowadays can bring numerous long-term financial benefits to society. Also, social security is exceptionally vital in order to assist individuals in supporting themselves. It is the foundation of family life; families can live securely, bolster their children, create 
community connections and care for the elderly. Without a decent living, it is troublesome to operate as a profitable part of the society. Other speculations in individuals that contribute to the financial success of society incorporate youth programs and administrations, postsecondary instruction, work creation, the advancement of sound and dynamic lives, and secure communities. [7]

Epidemics and economic crises in certain populations can have disproportionate impacts, resulting in worsening the problem of equity. We pinpointed some important aspects:

- The risk of people with underlying health issues and the elderly to develop serious health problems is greater.

- Young people are facing high unemployment rates, due to the global financial crisis, and are more likely to triggera decrease in workforce.

- Older employees may also face financial weaknesses. Following the MERS outbreak, it has been shown that high unemployment rates, under employment and few working hours are more likely among older people than people of working age.

- Women are overrepresented in most affected areas (e.g., services) or the leading occupations in the pandemic (e.g., Nurses). In comparison with 45.4 percent of working men, the ILO (International Labour Standards) estimates that $58.6 \%$ of working women worldwide are employed in the services sector.

- Unprotected workers, including gigs workers, are likely to be disproportionately affected in the absence of pay or sick leave schemes and under the protection of traditional social protection mechanisms and other sources of income.

- The effects of the COVID-19 crisis, restricting both their access to their jobs and the return to their families, make migrant workers more vulnerable.

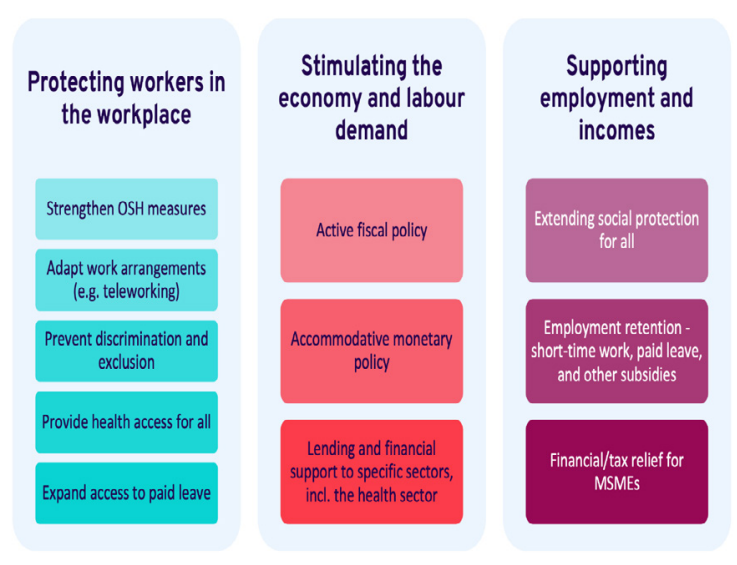

Figure 1: Policy framework: Three key pillars to fight Covid-19 based on the International Labour Standards

Source: International Labour Office, 2020

In the case of Romania, the migration process had a significant impact on the economic growth of Romania, according to the analysis of the European Commission, the World Bank and the International Monetary Fund. Almost a quarter of Romania's workforce has emigrated in the last 30 years. If this population had contributed to local economic activity, annual economic growth could have been 0.6 to 0.9 percentage points higher each year. The effects of this demographic phenomenon are unevenly distributed at the territorial level. Large urban populations, generally with higher and more productive levels of education, are more likely to be willing to emigrate. Young people between the ages of 15 and 34 in underdeveloped regions, such as the Northeast or the southern mountains, are also more likely to be willing to emigrate. The causes of these processes are many, but the lack of opportunities, the poor quality of public services, unequal access to them, the quality of physical and social infrastructure, or the lack of real opportunities for a satisfactory standard of living are the main triggers for this process [1]. 
In order to have the necessary manpower in the medium term, it is necessary to accelerate the process of retention of the workforce in the country and the repatriation of Romanians. In the current context, the diaspora is one of the strategic resources that Romania can mobilize to contribute to the process of economic growth and development, on an equal level as attracting investment and access to European funds.

Identifying specific measures and applying them to maintain the workforce in the country and reverse the exodus of information is an opportunity presented by the COVID-19 crisis. At the same time, studies show that when deciding to return to the country, in addition to possible incentives for Romanians abroad, other elements such as the quality of infrastructure, education and health systems, the degree of the digitization of public administration and air quality or the support of entrepreneurship are being taken into account. Therefore, we are struggling with a combination of factors that need to be tracked and translated into reality. These are also the elements that will reduce the amplitude of the phenomenon of emigration [3].

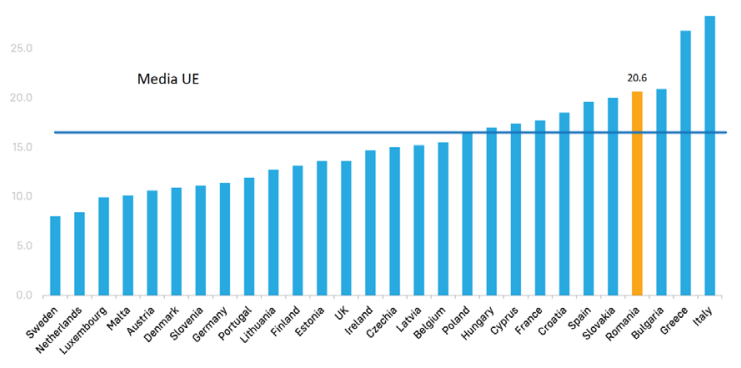

Figure 2:Young people aged between 20 and 34 outside the labour market and the education system

Source: Eurostat, 2020

According to the Romanian Ministry of Labour, Department of Sustainable Development, the coronavirus pandemic has fundamentally changed the landmarks of the world we live in. Mankind has entered a new dimension which has never been experienced before. They consider that the solution for the current crisis, for the reconstruction that follows, but also for the prevention of similar situations in the future, lies in the principles of sustainable development established by the 2030 Agenda established in 2015. Resilience, solidarity, the need to not leave anyone behind are more current than ever. The experts working in the field of sustainable development almost unanimously agree that the pandemic will inevitably have a major impact on the achievement of SDG's. A report published by the United Nations Economic and Social Committee mentions three possible scenarios: accelerating the transition to sustainable development; being at pace with the pandemic or worsening the situation. Beyond the technical details, the desideratum that should guide our actions in the next period is to turn the crisis into an opportunity for a solid and sustainable socio-economic reconstruction. The ways in which the coronavirus pandemic influences the implementation of some of the most important Sustainable Development Goals in the National Sustainable Development Strategy are presented down below. We mention that, at the moment, we can only have an overview. The effects certainly do not stop at those set out in this article. It will take some time until we can have the ability to analyse the real changes caused by the pandemic in detail [9].

\section{- WITHOUT POVERTY}

The health crisis caused by the coronavirus will inevitably generate, as most experts predict, a large economic crisis. For the first time in the last three decades, global poverty could rise, and more than half a billion citizens will fall below the poverty line, according to a recently published analysis by experts from the United Nations University - Institute for Economic Research Development. Under these conditions, the implementation of SDG 1 by 2030 will become a much more difficult mission, both worldwide and in Romania. To counteract some of these negative effects, a sustainable approach is needed, 
where public policies do take into account the impact on vulnerable groups. In the coming years, in addition to the public sector, both the private and non-profit sectors will have to act in a complementary way. The Department for Sustainable Development is currently coordinating the elaboration of the Action Plan for the implementation of the Strategy that will take into account the new socio-economic realities.

\section{- ZERO HUNGER}

The coronavirus pandemic has brought to attention the vital role that agriculture and the food industry play in the proper functioning of a society. In times of economic growth, there is less of an effort for ensuring food security. The lesson we should learn is that we need a competitive agricultural sector that allows citizens to have their supplies from local production.

\section{- HEALTH AND WELL-BEING}

Public health has unquestionably become the main concern of the society that we live in. It is very important that when we finally defeat the new type of coronavirus, we do not forget the disastrous effects it had. States need to be more prepared to deal with such phenomena. Therefore, it is essential to strengthen health systems, support medical research and strengthen the capacity to prevent and respond to pandemics or other widespread public health problems. Some of the tools needed for this approach lie in the strengthening of international organizations. The economy has been stagnant for a while and the effects are negative, but without isolation measures it is difficult to imagine how many times the number of diseases would have increased and how large the magnitude of the crisis would have become. This period can drive a rearrangement of society's priorities and put the health of citizens in the centre of attention. The crisis generated by the coronavirus has shown us that health is the vital engine of the society we live in. Improving services and grating access to quality healthcare is essential for the functioning of a sustainable patientcentred and preventive society. An appropriate framework for promoting a healthy and proactive lifestyle, prevention and medical education must be provided.

\section{- QUALITY EDUCATION}

One of the most significant problems in the Romanian education system is the inequality that has been brought to light due to the closure of schools during the pandemic. Online lessons were attended only by the students that had access to technology. Although the physical presence of kids and teachers at schools represents a significant part of the learning process and the educational system cannot be referred to as system that operates exclusively online, this time has shown us that access to digital education tools is a priority. The Sustainable Development Strategy sets Romania's the objectives for 2030: skillsoriented learning focused to address the student's need for greater freedom when defining study priorities; organizing vocational and technical training on especially designed and equipped campuses; increasing the level of financial education of citizens; modernizing the system of training.

\section{- CLEAN ENERGY}

It is extremely important that the European Commission's priorities on decarbonisation remain relevant even in the context of the pandemic. Some EU member states, including Romania, have spoken out in favour of using the European Ecological Pact as the main driver for economic reconstruction. European financial instruments must be used at their maximum efficiency because they have a huge potential to transform the energy sector in Romania into a more environmentally friendly one and at the same time to produce positive effects on a social level. In order to support the consumers' expectations in the long run, the Romanian 
energy sector must become more economically robust, more advanced, more technologically flexible, and less polluting.

\section{- DECENT WORK}

Given the labour shortage in Romania in recent years, the economic crisis generated by the pandemic may lead to the increase of unemployment rates. The labour market will most likely be severely affected, but the negative effects can be countered by investing in training and retraining. The country's 2030 challenges are to keep pace with the economic growth in order to reduce the gap with other EU Member States, to achieve increased productivity levels through diversification, technological modernisation and innovation; and to reinforce national financial institutions' ability to encourage and extend access to banking services. The pandemic raised the awareness of the whole society in its vision of the Department for Sustainability.

First of all, state institutions should formulate policy proposals and take those decisions which, in addition to reducing the effects, also ensure sustainable development in the medium and long term. We owe it to ourselves to have the courage to design a society after reconstruction in which the quality of life is at an even higher level than before the outbreak of the pandemic. In addition to the action of public authorities, however, the involvement of the private sector, experts in civil society, academia, research institutes, NGOs will also be needed. All these efforts will not have the desired impact if we fail to form a critical mass of citizens who believe in the principles of sustainable development and who put them into practice in their daily lives. According to the same source, the results of the labour market will be seriously affected by COVID-19 [11]

Besides employee's immediate health concerns, the labour market can be affected as such:
- the amount of jobs (which translates to both unemployment and low unemployment rates);

- the work quality;

- impact on specific groups, more susceptible of negative labour market impacts. Some workers are affected more by a lack of social security networks, such as young people working in precarious work, older or disabled people, women (as they have increased participation or remain home with relatives), self-employed or online workers, low wage workers, immigrants and people called "invisible workers", in other words, people who have a social security network. Poverty will also rise substantially.

The safeguarding of jobs and incomes of all workers is a priority, and current directives need to be designed for the long term. In order to revitalize the economy, protect the workers' rights, and ensure the well-being of everyone, the EU needs a strong social recovery and reconstruction strategy at national and EU level involving social partners actively.

Deeper policy and institutional reforms are necessary to reinforce confidence in institutions and governments in order to strengthen recovery and resilience through strong and universal social protection systems that can act as automatic economic and social stabilizers in times of crisis. The social dialogue, between governments, organizations and employers, is essential for building and implementing sustainable solutions at community and global level [12]. Strong social, independent and democratic partners are required in this respect. Special attention must be paid to ensuring that the recovery after the crisis is not being speeded up after the recent crisis. All groups must be supported, so that they can relax with each other without waiting as long as the rest of the population can see an improvement in employment and living standards. This applies in particular to young people, disabled people, ethnic minority members, immigrants and 
refugees. Particular attention should be paid to those non-employment groups who are already living in poverty, including new poverty groups that are expected to increase, and action is needed. These groups are in danger of being further marginalized and of facing a number of social and health problems. The CSOs themselves are victims of the weaknesses and inequalities of the system.

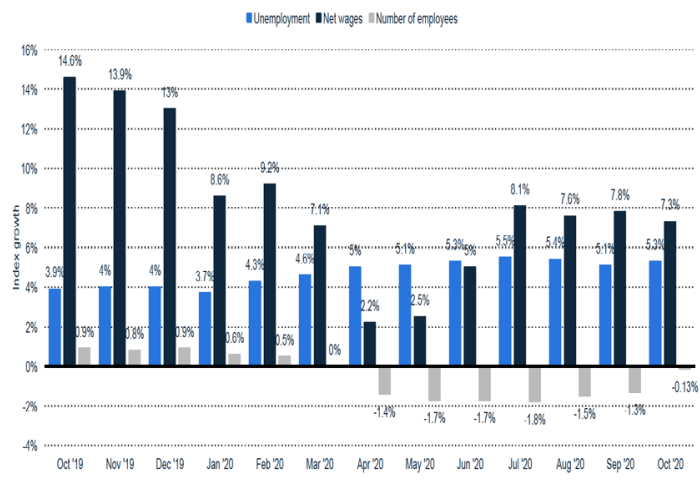

Figure 3: Impact of the coronavirus (COVID-19) outbreak on the labour market indicators in Romania from October 2019 to October 2020. Labour market indices in Romania, including the impact of the COVID-19pandemic in 2019-2020.

Source: Statista, 2021

\section{Key policies for mitigating the effects of the COVID-19 pandemic on social development in the European Union}

When calling for a green transformation, a strong social recovery and a strong economic recovery, the Commission argues that such an ambitious and transformative plan can come about through six principles: solidarity, competitiveness, sustainability, protection of jobs, income and participation. In this respect, Europe is more credible and capable of meeting the unprecedented challenges faced by the more intensive and adapted recovery efforts for each Member State and for its people [6].

- An important step for the proactive initiation of a process of social convergence is the European Subject to Social Rights (ESDP) at European level and in all
Member States. ESDP is the tool for creating a new and up-to-date social image.

- The importance of knowledge and the ongoing use of education, education and lifelong learning system that allows European workers to adapt to changes. The education system must be placed at the heart of the EU strategy. Employment should be emphasized. Digital and environmental change in production.

- Redefinition is vital in the postCOVID-19 recovery period. The continuous growth in productivity has in most of the European Union undermined the quality of services and work experience in the public and private healthcare and health sectors, with a dramatic impact during the health crisis. Transfer to serviceoriented activities would lead to a labourintensive economy that offsets the unstable nature of jobs in these sectors and fosters higher levels of employment and job creation. Consequently, guidelines are important to support good work in highquality, high-level labour sectors.

- As a pledge to preserve the social dimension, the EESC welcomes the European Commission's updated Work Program for 2020. A number of legislative and non-legislative initiatives are not postponed or delayed because they represent the pillars of the social agenda. These include: the implementation of guidelines adopted under the already approved programme (guidelines on reconciling work and personal life, guidelines on posting of workers, guidelines on transparent and predictable working conditions). The Commission has also confirmed all the initiatives which lead to a just and socially sustainable recovery, including those concerning salary transparency, minimum wages, fair taxes, youth employment, the European reinsurance system for the jobless and the skills agenda. The work program does not provide the updating of health and safety criteria at the workplace by means of effective prevention measures. 
- Strong social recovery also means improving access to protection. Labour markets should be supported in collective bargaining and democracy. The EU and the Member States have to contribute to the social partners' increase in the percentage of collective agreements.

- It is also important to address the role of gender equality. The current COVID-19 epidemic has a significant effect on gender equality during the isolation and the subsequent recovery phase, as a result of the economic slowdown. The fall in jobs as a result of physical distancing has an important impact in sectors where women are highly compared to regular recessions, which affect employment of women more than that of men. Moreover, closing schools and day care centres, which particularly affected maternity workers, led to an enormous increase in the need for day-care facilities. In view of the value of their work experience, the impact of the crisis on female workers is likely to continue.

The Coronavirus pandemic took us all by surprise. Regardless of nationality, training, social status or professional activity, the landmarks of the world we live in have suddenly changed. The effects on each of us were smaller or larger, but they certainly existed. Suddenly we have all become vulnerable to an invisible enemy that attacks its victims regardless of their place in society. The health challenge was quickly reflected in the economy. Most of the developed countries have closed for various periods of time so as to slow down the spread of the virus and find that respite needed to strengthen the capacity of health systems to manage the pandemic. Thus, a first principle that must underlie the postpandemic construction can be formulated: not only the world is interconnected, but also all sectors of the socio-economic life. A crisis in one sector has an effect on others. This evolution is a first indicator that we need a holistic approach when trying to find solutions to contemporary problems.
The health crisis occurred at a time when there was a growing need to change the economic development model. Australia faced unparalleled wildfires earlier last year. Extreme weather events are becoming increasingly prevalent. Romania has until now been protected from major disasters, but some atypical situations such as the 2019 tornado have also been observed at the national level. The environmental impact of human activity is becoming increasingly visible. The traditional consumer-oriented development paradigm has raised welfare to a certain level, but has showed its limits. In order to address the challenges of the 21 st century, Romania requires a change in the current paradigm for development. We live in a period of globalization, increasing inequalities and worsening environmental issues. We need a new approach and sustainable development provides us with solutions to most of today's problems [8].

Romania has also adopted the 2030 Agenda and its 17 Sustainable Development Goals. In April 2016 the Romanian parliament was the first of the 176 others to express its support for implementing the 2030 Agenda in Romania by holding a joint meeting between the two Chambers. Since 2017, within the Government's working apparatus, the Department for Sustainable Development has been established to coordinate the implementation on a national level of the 17 Sustainable Development Goals.

The Department's most significant outcome is the review of the Romania 2030 National Sustainable Development Strategy. The general view is that sustainable development represents a framework of thinking which, once mastered by the people, it will contribute to creating a more equitable, balanced and solid society that addresses changes caused by current world, regional and national problems, including demographic decline. The State's concern for the citizen and its respect for the institutions, for its neighbour, for moral and 
cultural values and for ethnic diversity are all conducive to a sustainable society.

The basic principles promoted in Romania's Agenda and National Sustainable Development Strategy 2030 are resilience, solidarity, the need to not anyone leave behind. They are more relevant than ever for today's socio-economic crisis. The experts working on sustainable development are unanimous in their acceptance of the pandemic's inevitable consequences for the implementation of the Sustainable Development Objectives. A UN Economic and Social Committee report mentions three possible scenarios: speeding up the transition towards sustainable development, keeping pace with the pandemic or the aggravation of the situation.

In addition to technical details, our actions should be guided in the coming period in order to turn the crisis into an opportunity for a socio-economic reconstruction that is solid and sustainable. Our road to 17 Sustainable Development Objectives is drawn mainly by us. The more anchored in this new paradigm national policies are, the more opportunities we have not only to overcome the crisis, but to build a resilient, fairer and environmentally friendlier society. We offered a number of concrete examples from the perspective of sustainable development of fundamental principles that should underlie the postpandemic reconstruction.

The country's 2030 challenges are to keep pace with the economic growth in order to reduce the gap with other EU Member States, to achieve increased productivity levels through diversification, technological modernisation and innovation; and to reinforce national financial institutions' ability to encourage and extend access to banking services. Every Sustainable Development Goal can continue. The main idea is that the complex issues we are being confronted with require a holistic approach that takes into consideration the impact of a certain policy on other sectors. In order not to neglect the ethical component, we also need decisions and actions.

In the vision of the Department for Sustainable Development, the consequences of the pandemic raise the awareness of the whole society. First of all, state institutions should formulate policy proposals and take those decisions which, in addition to reducing the effects, also ensure sustainable development in the medium and long term. We owe it to ourselves to have the courage to design a society through reconstruction in which the quality of life is at an even higher level than before the outbreak of the pandemic. In addition to the action of public authorities, however, the involvement of the private environment, experts from civil society, academia, research institutes, NGOs will also be needed. All these efforts will not have the desired impact if we fail to form a critical mass of citizens who believe in the principles of sustainable development and who put them into practice in their daily lives [10].

\section{Conclusions}

The New Economy of the European Union and implicitly the New Economy of Romania are massively oriented towards sustainable development and will help us build a Sustainable Romania. This new economy needs effective European policies for all Member States that realistically take into account the resources, capabilities and opportunities of each Member State. Any type of crisis has dramatic effects on society and people's well-being. However, whenever we relate to such difficult moments, we are obliged to always have the ability to identify the positive parts even if they sometimes are very difficult to find. Hope and a dose of optimism are often part of the lessons we should learn during the reconstruction stage. In these turning points, we need to lucidly look at how the contemporary society works and keep an eye on those mechanisms that can be improved. Socio-economic reconstruction 
is therefore not just a step towards overcoming the crisis, but it is an opportunity to improve the world we live in and which we have to pass onto the future generations.

\section{References List}

[1] Baldwin; Di Mauro 2020. Economics in the Time of Covid-19. Available at: https://voxeu.org/content/economics-time-covid-19., (accessed February 2021).

[2] Baldwin, R.; Tomiura, E. Thinking Ahead about the Trade Impact of COVID-19. Available online: https://voxeu.org/content/mitigating-covid-economic-crisis-act-fastand-do-whatever-it-takes., (accessed January 2021).

[3] Border Biosecurity Must Be Reinvented to Restart Economies, BCG, available at: https://www.bcg.com/publications/2020/border-biosecurity-to-restart-economies., (accessed February 2021).

[4] COVID-19 and the world of work: Impact and policy responses, March 2020, Available at:https://www.ilo.org/wcmsp5/groups/public/---dgreports/--dcomm/documents/briefingnote/wcms_738753.pdf?fbclid=IwAR3tQQCAFQ8ECVOL8m W4BAFRmTOUd2wNfBkBnCty4PqhrnNxmVbEs8JjNFc., (accessed February 2021).

[5] EU invisible on social emergency of COVID-19, European Association of Service providers for Persons with Disabilities, available at: https://www.easpd.eu/en/content/eu-invisible-social-emergency-covid-19., (accessed February 2021).

[6] Everyone Included: Social Impact of COVID-19, United Nations, https://www.un.org/development/desa/dspd/everyone-included-covid-19.html., (accessed February 2021).

[7] McKibbin, W. and R. Fernando, 2020. The Global Macroeconomic Impacts of COVID19: Seven Scenarios. Available at: https://www.brookings.edu/research/the-globalmacroeconomic-impacts-of-covid-19-seven-scenarios/., (accessed January 2021).

[8] Mihaela Rus \& Mihaela Luminita Sandu \& Tasente Tanase, 2020. Covid-19 crisis in Romania - between perception and attitude. Available at: https://econpapers.repec.org/article/tecjournl/v_3a6_3ay_3a2020_3ai_3a1_3ap_3a6987.htm., (accessed January 2021).

[9] Nicola M, Alsafi Z, Sohrabi C, et al., 2020. The socio-economic implications of the coronavirus pandemic. Available at: https://www.euro.who.int/en/countries/romania., (accessed January 2021).

[10] Sanjay Bhattacharya, The Social Impact of the COVID-19 Pandemic, 2020, Observer Research Foundation, Available at: https://www.orfonline.org/research/the-socialimpact-of-the-covid19-pandemic/., (accessed February 2021).

[11] Social support is leading the way out of the crisis, European Commission, Available at: https://ec.europa.eu/info/strategy/recovery-plan-europe/recovery-coronavirus-successstories/eu-values-and-citizens-rights/social-support-leading-way-out-crisis_en., (accessed February 2021).

[12] The impact of coronavirus in Romania from the perspective of the 2030 Agenda, Available at: https://progeu.regione.emilia-romagna.it/en/faircities/news-from-thepartners/the-impact-of-coronavirus-in-romania-from-the-perspective-of-agenda-2030., (accessed February 2021). 